\title{
Effect of Social Media on Patient's Perception of Dental Aesthetics in Saudi Arabia
}

\author{
Khadijah M. Baik $\mathbb{D}^{1},{ }^{1}$ Ghazal Anbar $\mathbb{D D}^{2}$ Abeer Alshaikh, ${ }^{2}$ and Arwa Banjar $\mathbb{D D}^{3}$ \\ ${ }^{1}$ Oral and Maxillofacial Prosthodontics Department, Faculty of Dentistry, King Abdulaziz University, Jeddah, Saudi Arabia \\ ${ }^{2}$ BDS, Faculty of Dentistry, King Abdulaziz University, Jeddah, Saudi Arabia \\ ${ }^{3}$ Department of Periodontology, Faculty of Dentistry, King Abdulaziz University, Jeddah, Saudi Arabia
}

Correspondence should be addressed to Khadijah M. Baik; kbaik@kau.edu.sa

Received 14 November 2021; Revised 20 December 2021; Accepted 31 January 2022; Published 27 February 2022

Academic Editor: Alessandro Leite Cavalcanti

Copyright () 2022 Khadijah M. Baik et al. This is an open access article distributed under the Creative Commons Attribution License, which permits unrestricted use, distribution, and reproduction in any medium, provided the original work is properly cited.

\begin{abstract}
Introduction. Social media became an influential tool that affects people's way of communication and became a significant source of information for the society. The study aimed to evaluate the impact of SM on patients seeking aesthetic dental treatment. Methodology. The study employed a large-scale online survey of 1940 patients attending and/or seeking dental treatment at KAUFD and Jeddah private clinics. The targeted age of participants ranged from 18 years and above. The study data were collected using a three-part questionnaire. Results. More than half of the patients were females in both groups (52.7\%). The majority of patients used SM for communication and entertainment purposes. It was also found that the most popular platform used by patients was Snapchat (71.1\%), followed by Instagram (66.9\%). A lot of patients did not like their teeth appearance (38.5\%). Moreover, patients preferred to have "bleaching" as an aesthetic treatment to improve their smiles (63.8\%). Conclusion. The impact of SM on Saudi Arabian citizens and Saudi Arabia residents can be considered as high. Patients are influenced by SM applications and are seeking aesthetic treatment as an outcome. It is the responsibility of dentists to educate patients about the best treatment options.
\end{abstract}

\section{Introduction}

Social media (SM) is a powerful tool that affects not only communication but also relationships among people. SM nowadays is called a social-cultural agent of change that uses information and affects the provider-patient interaction. SM has begun to spread across the medical field, and nowadays, patients take it as a source of information. It is considered a useful tool for the dentist and the patient [1]. Even though patients use SM in their personal lives, little is known about their attitudes and expectations toward using SM for professional interactions. SM marketing is a more useful marketing technique compared to traditional marketing. A study conducted in Riyadh among dentists reported that Twitter was the most commonly used platform, where $43 \%$ reported that they use SM for educational purposes. It was also reported that $62 \%$ and $68 \%$ used SM to promote their dental practice and broadcast treatment outcomes, respectively [2]. Smile aesthetics can provide valuable insights into posttreatment satisfaction and can predict the patients' goals for receiving treatment [3].

SM has a strong impact on people's lives, and it is similar in Saudi Arabia and the Arabian Gulf region [4]. Patients look for dental information, follow and connect with dentists, and write about their experience through SM. In Saudi Arabia, it is reported that the majority of participants preferred receiving health-related information from trusted official sources [5]. The outcomes of dental aesthetic treatment have a huge psychological impact on the patients, where poor outcomes may damage the dentist-patient relationship. Dentists should know how to get patients' attention to dental problems and their treatments by posting cases on SM in a simple manner that the people easily understand. This will encourage patients to seek dental treatment and raise their awareness about the actual treatments and their benefits. In addition, patients could use 
SM to have background information about dental treatments and their indications, especially if it is from an aesthetic view. Also, they need to know how to communicate with their dentists and ask more about the aesthetic treatments before any interventions such as an "online consultation," which will make patients more comfortable and confident with their dental staff. There is rapid growth and influence of SM on patients' behaviors, but until now, there is not sufficient evidence about the effect of SM on demand for aesthetic dental treatment in Saudi Arabia. Thus, this study aim is to check the impact of SM effect on patients seeking aesthetic dental treatment.

\section{Materials and Methods}

A cross-sectional analytical study was carried out since September 2019 among patients seeking dental treatment in Jeddah city, Saudi Arabia. The questionnaire was distributed to patients seeking dental treatment at King Abdulaziz University Faculty of Dentistry (KAUFD) dental hospital as well as private clinics. The study sample consisted of 1940 random patients (50\% from KAUFD and $50 \%$ from private clinics), and the time for completion of the said study was 56 days ( 8 weeks). The inclusion criteria were patients who ranged from 18 to older than 45 years and came to KAUFD and private clinics for dental treatments. All nationalities and socioeconomic status levels will be included, and geriatric (over 60 years old) and pediatric (below 18 years old) patients will be excluded. Human subject protection was taken into consideration by explaining the purpose and the procedure of the current study to participating patients. Consequently, ethical approval was released to begin this research (REC no. 155-11-19) from the Research Ethics Committee, Faculty of Dentistry, King Abdulaziz University.

For test-retest reliability, 10 individuals were asked to complete the survey, and then they repeated the survey a second time after a one-week period. A pretested questionnaire was used for data collection that had three parts: (a) sociodemographic data, (b) patients' satisfaction of their current dentition from the aesthetic view, and (c) questions regarding SM applications and their usage related to dental purposes. There were a total of 28 questions, with an estimated time to complete the survey to be around 5-10 minutes. Consent e-forms were then provided and distributed electronically to all participants, using "SurveyMonkey" program. Questionnaires were distributed and collected either in person using electronic tablets or were sent via WhatsApp application messages. Participants had the option of either filling the survey in Arabic or English language.

2.1. Statistical Analysis. A minimum sample size of 1123 was calculated assuming a proportion of 0.5 and desired precision of the estimate was 0.05 and at a $95 \%$ confidence level. Sample size estimating software used was nMaster 2.0. (CMC, Vellore). The Statistical Package for Social Sciences, version 23 (SPSS Inc., Chicago, IL, USA), was used for the data analysis. Categorical variables were presented as numbers and percentages. Continuous variables were measured using mean and standard deviation. Pearson's chi-square test was used to find an association between categorical variables. A $p$ value less than 0.05 was considered statistically significant.

\section{Results}

The analysis included a total response from 1940 participants from KAUFD clinical (50\%) and private dental clinics (50\%). The sociodemographic characteristics showed that $52.7 \%$ were females, $32 \%$ belonged to $18-25$ years, $57 \%$ were married, $77.6 \%$ were Saudi citizens, $49.2 \%$ had a graduate level of education, and $43.6 \%$ belonged to medical sectors. When we assessed the satisfaction about the shape and color of their natural teeth, $38.5 \%$ reported that they did not like them. Among this, 29.5\% $(n=220)$ reported that this dislike was after following a dental/dentist account or page in SM. The most common aesthetic dental treatment preferred to be done is bleaching (63.8\%) followed by orthodontics (39.4\%), crowns $(30 \%)$, and veneers $(21.2 \%)$. The most common reason to choose the above aesthetic dental treatment was recommendation from family and friends $(76.2 \%)$, whereas only $12.7 \%$ mentioned it as "SM" impact, and $5.1 \%$ did this due to "followers and like" for the dental or dentist's account or page in SM. It was reported by $51.6 \%$ that a 'specialist or consultant' did the treatment, and $59.5 \%$ were satisfied with this treatment. When we analyzed the relationship between these two, it was found that participants were comparatively more satisfied with the treatment that is performed by a specialist or consultants $(57.3 \%)$ than that done by the general dentist (42.7\%), which showed a statistical significance $(p<0.001)$ (Figure 1$)$.

The most common aspect of the teeth that participants were dissatisfied with was chipped or broken teeth $(50 \%)$, followed by tooth shape $(38.7 \%)$, gum health $(37.1 \%)$, and tooth color $(33.9 \%)$, where $91.9 \%(n=114)$ reported that they would attempt for another treatment for its correction (Table 1).

It was believed by a majority of the participants $(79.7 \%)$ that dental prosthesis is not lifelong. When we asked participants' perception about the life expectancy of veneers and crowns, $47.8 \%$ believed that it is less than 10 years, whereas only $23 \%$ mentioned it as more than 10 years. The practices related to SM usage showed $92.1 \%$ used social media (SM), where Snapchat $(71.1 \%)$ was the commonly used one and $86.7 \%$ of them used SM daily. The most common purpose for its usage was for 'communication' (77.6\%), and it was found that only $36.6 \%$ followed a dental or dentist's account on SM (Table 2).

The usage of SM was comparatively more seen in females (94.1\%), participants aged $18-25$ years $(98.1 \%)$, who were single $(97.1 \%)$, participants who had educational qualification at the graduate level (94.5\%), and whose profession was engineering $(95.6 \%)$ than others $(p<0.001)$. Their usage was comparatively low in participants who had a monthly income of more than 15,000 SAR $(84.8 \%)$ than others $(p<0.001)$ (Table 3).

When we assessed the pattern of SM usage between two genders, participants who followed dentists'/dental accounts in SM were comparatively females $(43 \%, p<0.001)$, aged 


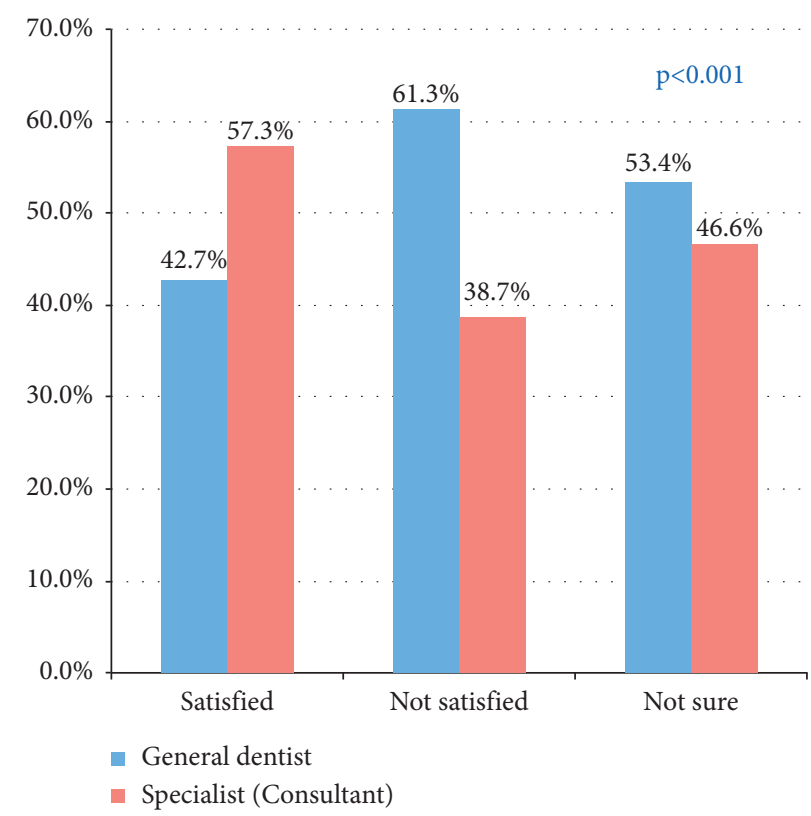

FIGURE 1: Relationship between satisfication about treatment done and the person performed it $(n=740)$.

TABLE 1: Baseline characteristics of the participants.

\begin{tabular}{|c|c|c|c|}
\hline & & $N$ & $\%$ \\
\hline \multirow{2}{*}{ Gender } & Male & 918 & 47.3 \\
\hline & Female & 1022 & 52.7 \\
\hline \multirow{4}{*}{ Age } & $18-25$ & 620 & 32.0 \\
\hline & $26-35$ & 412 & 21.2 \\
\hline & $36-45$ & 430 & 22.2 \\
\hline & $>45$ & 478 & 24.6 \\
\hline \multirow{3}{*}{ Social status } & Single & 770 & 39.7 \\
\hline & Married & 1106 & 57.0 \\
\hline & Divorced & 64 & 3.3 \\
\hline \multirow{2}{*}{ Nationality } & Saudi & 1506 & 77.6 \\
\hline & Non-Saudi & 434 & 22.4 \\
\hline \multirow{5}{*}{ Educational qualification } & No primary education & 10 & .5 \\
\hline & High school & 688 & 35.5 \\
\hline & Diploma & 158 & 8.1 \\
\hline & Bachelor degree & 954 & 49.2 \\
\hline & Masters/PhD & 130 & 6.7 \\
\hline \multirow{6}{*}{ Job sectors } & Medical & 846 & 43.6 \\
\hline & Engineering & 364 & 18.8 \\
\hline & Educational & 212 & 10.9 \\
\hline & Fashion and business & 202 & 10.4 \\
\hline & Accounting & 164 & 8.5 \\
\hline & Others & 152 & 7.8 \\
\hline \multirow{4}{*}{ Income (SAR) } & $<5000 \mathrm{SAR}$ & 376 & 19.4 \\
\hline & 5000-15000 SAR & 516 & 26.6 \\
\hline & $>15000$ & 330 & 17.0 \\
\hline & No salary & 718 & 37.0 \\
\hline
\end{tabular}

18-25 years $(47.4 \%, p<0.001)$, those who had bachelor degree $(38.6 \%, p=0.040)$, and those who belonged to the medical sector $(41.2 \%)$ more than others. When asked whether the dental content in SM is accurate or not, participants aged $26-35$ years $(11.1 \%, p=0.015)$, non-Saudi nationalities $(10.9 \%, p<0.001)$, those who had diplomas (14.9\% $p<0.001)$, and those from the educational sector
$(10.8 \%, p<0.001)$ comparatively more agreed that it is accurate than others. When participants were asked whether the photos of the dental treatment outcome (before/after) encourage patients to seek treatment, females (57\%, $p=0.006)$, participants aged $26-35$ years $(60.1 \%, p<0.001)$, non-Saudi nationals $(56.7 \%, p=0.043)$, participants with the education of high school level $(58.3 \%, p=0.001)$, and those 
TABLE 2: Satisfaction and attitudes about dental aesthetics.

\begin{tabular}{|c|c|c|c|}
\hline & & $n$ & $\%$ \\
\hline \multirow{3}{*}{ Likes the shape/color of your current teeth $(n=1940)$} & Agree & 578 & 29.8 \\
\hline & Disagree & 746 & 38.5 \\
\hline & Not sure & 616 & 31.8 \\
\hline \multirow{3}{*}{$\begin{array}{l}\text { If does not like the teeth, it was after following dental accounts/public figures in social } \\
\text { media }(n=746)\end{array}$} & Agree & 220 & 29.5 \\
\hline & Disagree & 292 & 39.1 \\
\hline & Not sure & 234 & 31.4 \\
\hline \multirow{8}{*}{ Aesthetic dental treatment likes to be done for your teeth $(n=746)$} & Orthodontic & 294 & 39.4 \\
\hline & Bleaching & 476 & 63.8 \\
\hline & Crown & 224 & 30.0 \\
\hline & Veneers & 158 & 21.2 \\
\hline & Crown lengthening surgery & 70 & 9.4 \\
\hline & Filler injection for the face & 38 & 5.1 \\
\hline & Botox injection & 28 & 3.8 \\
\hline & Others & 24 & 3.2 \\
\hline \multirow{2}{*}{ Did dental consultation for the aesthetic problem $(n=1940)$} & Yes & 950 & 49.0 \\
\hline & No & 990 & 51.0 \\
\hline \multirow{2}{*}{ Did aesthetic dental treatment in the past 5 years $(n=1940)$} & Yes & 740 & 38.1 \\
\hline & No & 1200 & 61.9 \\
\hline \multirow{7}{*}{ Type of aesthetic dental treatment done $(n=740)$} & Bleaching & 34 & 4.6 \\
\hline & Veneers & 236 & 31.9 \\
\hline & Crowns & 292 & 39.5 \\
\hline & Crown lengthening surgery & 30 & 4.1 \\
\hline & Orthodontics & 240 & 32.4 \\
\hline & Filler injection for the face & 10 & 1.4 \\
\hline & Botox injection & 14 & 1.9 \\
\hline \multirow{6}{*}{ Reasons made to choose the above aesthetic dental treatment $(n=740)$} & $\begin{array}{l}\text { Recommendation from family and } \\
\text { friends }\end{array}$ & 564 & 76.2 \\
\hline & Social media & 94 & 12.7 \\
\hline & Special offers & 114 & 15.4 \\
\hline & Followers and likes & 38 & 5.1 \\
\hline & Certificates and awards of the dentist & 66 & 8.9 \\
\hline & Quality of before/after pictures & 78 & 10.5 \\
\hline \multirow{2}{*}{ Person who did aesthetic dental treatment $(n=740)$} & General dentist & 358 & 48.4 \\
\hline & Specialist/consultant & 382 & 51.6 \\
\hline \multirow{3}{*}{ You are satisfied with your dental treatment you had done $(n=740)$} & Satisfied & 440 & 59.5 \\
\hline & Not satisfied & 124 & 16.8 \\
\hline & Not sure & 176 & 23.8 \\
\hline \multirow{7}{*}{ Aspect of teeth that did not give satisfaction $(n=124)$} & Tooth shape & 48 & 38.7 \\
\hline & Tooth color & 42 & 33.9 \\
\hline & Chipped or broken teeth & 62 & 50.0 \\
\hline & Bulky teeth & 20 & 16.1 \\
\hline & Gum health & 46 & 37.1 \\
\hline & Oral smell & 34 & 27.4 \\
\hline & $\begin{array}{c}\text { Effect on facial profile } \\
\text { Others }\end{array}$ & 12 & 9.7 \\
\hline \multirow{2}{*}{ Attempt another treatment to correct it $(n=124)$} & Yes & 114 & 91.9 \\
\hline & No & 10 & 8.1 \\
\hline
\end{tabular}

TABle 3: Perception about dental prosthesis.

\begin{tabular}{|c|c|c|c|}
\hline & Responses & $N$ & $\%$ \\
\hline \multirow{3}{*}{ Think that the dental prosthesis is for life } & Yes & 372 & 19.2 \\
\hline & No & 1546 & 79.7 \\
\hline & Not sure/do not know & 22 & 1.1 \\
\hline \multirow{3}{*}{ Life expectancy of veneers and crowns } & $<10$ years & 928 & 47.8 \\
\hline & 10 years & 566 & 29.2 \\
\hline & $>10$ years & 446 & 23.0 \\
\hline
\end{tabular}


TABle 4: Practices related to social media use.

\begin{tabular}{|c|c|c|c|}
\hline & & $N$ & $\%$ \\
\hline \multirow{2}{*}{ Use any social media app } & Yes & 1786 & 92.1 \\
\hline & No & 154 & 7.9 \\
\hline \multirow{4}{*}{ Type of social media apps used $(n=1786)$} & Instagram & 1194 & 66.9 \\
\hline & Snapchat & 1270 & 71.1 \\
\hline & Facebook & 456 & 25.5 \\
\hline & Twitter & 1014 & 56.8 \\
\hline \multirow{4}{*}{ Frequency of its usage $(n=1786)$} & Daily & 1548 & 86.7 \\
\hline & Monthly & 30 & 1.7 \\
\hline & Rarely & 140 & 7.8 \\
\hline & Weekly & 68 & 3.8 \\
\hline \multirow{4}{*}{ Purpose of its usage } & Communication & 1386 & 77.6 \\
\hline & Entertainment & 1274 & 71.3 \\
\hline & Education & 1082 & 60.6 \\
\hline & Advertisement & 338 & 18.9 \\
\hline \multirow{2}{*}{ Follow any dental or/and dentist account } & Yes & 654 & 36.6 \\
\hline & No & 1132 & 63.4 \\
\hline \multirow{3}{*}{ All dental contents present in social media are accurate } & Agree & 134 & 7.5 \\
\hline & Disagree & 784 & 43.9 \\
\hline & Not sure & 868 & 48.6 \\
\hline \multirow{3}{*}{ Photos of the dental treatment outcome (before/after) encourage patients to seek treatment } & Agree & 966 & 54.1 \\
\hline & Disagree & 194 & 10.9 \\
\hline & Not sure & 626 & 35.1 \\
\hline
\end{tabular}

who belonged to the medical sector $(56 \%, p=0.019)$ were the ones who agreed comparatively more to this than others (Table 4).

\section{Discussion}

SM has become a very influential tool that affects our communication and relationships with people, and like every other tool, it has its pros and cons. SM nowadays is called a "social-cultural agent of change" that uses data to alter the provider-patient interaction. The use of SM in the medical field has grown exponentially and has become one of the main sources of information for the patient. In fact, it is considered a useful tool for the dentist and the patient; even though the patients use SM in their personal lives, we still do not know enough about their attitudes and what they expect from its interactions [6]. The current study shows that SM marketing for dentists is more useful compared to traditional marketing practices. Studies show that most of the dentists recommended the usage of SM by their colleagues because it had a significant effect on their career, and the majority had a positive effect on their dental practice $[3,7]$. As far as the patients are concerned, there are many patients who are already using different SM to connect with their dentists. In our study, younger age groups were more frequent users of SM, and the majority was females because it affected their choices, especially in the aesthetic field and different kinds of treatments. At the present time, aesthetic dental treatment has become a priority for most of the population, but not all patients know what the causes might be and parameters that affect the appearance of the smile, dental arch characteristics, dentogingival, and dentolabial [8]. Smile aesthetics have a huge effect on patient satisfaction and patient expectations in the ongoing treatment [9].
According to research conducted among dental students, females were more concerned and critical about dental aesthetics, with hypodontia being the most distracting feature of a smile when assessing its beauty, followed by a gingival smile, a reversed occlusal plane, and dental crowding [10]. Protrusion of teeth, poorly aligned teeth, carious and discolored restorations, and fractured teeth all influence the dental appearance of the patients $[10,11]$. A cross-sectional study was done in one of the dental schools in the United Kingdom to examine SM use, perceptions, and attitudes towards SM and the survey in the study reported that most of the participants were using SM at least once a week; more than one application and a majority had an idea about how can SM affect their dental practice positively [12]. Another study done in Saudi Arabia reported that 98\% of the participants had at least one account on SM, $81 \%$ used it daily, and $66 \%$ of patients used it as a source of information [13]. Dentists may be unable to take advantage of SM activities that benefit both dentists and patients due to a lack of understanding of patients' attitudes toward utilizing SM for dental treatment purposes. A study done in New Zealand among general dental practitioners showed that television affects the population in seeking for various aesthetic dental procedures, mainly bleaching and veneers [14]. Dental practitioners may also face problems managing their professional image and relationships with patients as a result of widespread and rapid access to information $[15,16]$. Patients and dentists may face additional problems that threaten their privacy as a result of their use of SM. It is reported that dentists do not well understand concepts, methods, and processes linked to SM communication [17]. Some concerns, such as after-clinic care and dental anxiety, can be addressed via social networks. Dental anxiety is a serious issue in dentistry, which often causes depression, sleep disorders, an 
unwillingness to establish intimate interpersonal relationships, and difficulty at workplaces $[18,19]$. Wider qualitative research may allow us to analyze successful cases of SM usage in dentistry, which would provide some specific suggestions for dental professionals. It is the responsibility of dentists to educate patients about the best treatment option.

\section{Conclusion}

The study confirmed that SM has recently become a priority in the Saudi population, and it developed very quickly. Also, it becomes an important tool in most of our daily life needs such as communication, education, entertainment, and healthcare. Therefore, the impact of SM on Saudi Arabian citizens and Saudi Arabia residents can be considered as high. Patients are influenced by the SM applications and are seeking aesthetic treatment as an outcome.

\section{Data Availability}

The data presented in this study are available within the article.

\section{Conflicts of Interest}

The authors declare that they have no conflicts of interest.

\section{References}

[1] H. Spallek, S. P. Turner, E. Donate-Bartfield et al., "Social media in the dental school environment, Part A: benefits, challenges, and recommendations for use," Journal of Dental Education, vol. 79, no. 10, pp. 1140-1152, 2015.

[2] K. S. Al-Khalifa, A. S. Al-Swuailem, R. AlSheikh et al., "The use of social media for professional purposes among dentists in Saudi Arabia," BMC Oral Health, vol. 21, no. 1, p. 26, 2021.

[3] N. Parmar, L. Dong, and A. B. Eisingerich, "Connecting with your dentist on facebook: patients' and dentists' attitudes towards social media usage in dentistry," Journal of Medical Internet Research, vol. 20, no. 6, Article ID e10109, 2018.

[4] S. A. AlSadrah, "Social media use for public health promotion in the Gulf Cooperation Council," Saudi Medical Journal, vol. 42, no. 1, pp. 9-20, 2021.

[5] M. S. Alhaddad, "The use of social media among Saudi residents for medicines related information," Saudi Pharmaceutical Journal, vol. 26, no. 8, pp. 1106-1111, 2018.

[6] E. Smailhodzic, W. Hooijsma, A. Boonstra, and D. J. Langley, "Social media use in healthcare: a systematic review of effects on patients and on their relationship with healthcare professionals," BMC Health Services Research, vol. 16, no. 1, p. 442, 2016.

[7] R. H. Bahabri and A. B. Zaidan, "The impact of social media on dental practice promotion and professionalism amongst general dental practitioners and specialists in KSA," Journal of Taibah University Medical Sciences, vol. 16, no. 3, pp. 456-460, 2021.

[8] M. Bhuvaneswaran, "Principles of smile design," Journal of Conservative Dentistry, vol. 13, no. 4, pp. 225-232, 2010.

[9] M. N. Alhajj, Z. Ariffin, A. Celebić, A. A. Alkheraif, A. G. Amran, and I. A. Ismail, "Perception of orofacial appearance among laypersons with diverse social and demographic status," PLoS One, vol. 15, no. 9, Article ID e0239232, 2020 .
[10] J. Armalaite, M. Jarutiene, A. Vasiliauskas et al., "Smile aesthetics as perceived by dental students: a cross-sectional study," BMC Oral Health, vol. 18, no. 1, p. 225, 2018.

[11] D. M. Ajayi, S. O. Gbadebo, and G. E. Adebayo, "Perception about tooth colour and appearance among patients seen in a tertiary hospital, South-West, Nigeria," The Pan African Medical Journal, vol. 38, p. 38, 2021.

[12] P. Kenny and I. G. Johnson, "Social media use, attitudes, behaviours and perceptions of online professionalism amongst dental students," British Dental Journal, vol. 221, no. 10, pp. 651-655, 2016.

[13] M. Aldaij, T. Alshehri, A. Alzeer et al., "Patient satisfaction with dental appearance and treatment desire to improve esthetics," Journal of Oral Health and Community Dentistry, vol. 12, no. 3, pp. 90-95, 2018.

[14] A. H. Theobald, B. K. Wong, A. N. Quick, and W. M. Thomson, "The impact of the popular media on cosmetic dentistry," New Zealand Dental Journal, vol. 102, no. 3, pp. 58-63, 2006.

[15] P. Neville and A. Waylen, "Social media and dentistry: some reflections on e-professionalism," British Dental Journal, vol. 218, no. 8, pp. 475-478, 2015.

[16] K. Rolls, M. Hansen, D. Jackson, and D. Elliott, "How health care professionals use social media to create virtual communities: an integrative review," Journal of Medical Internet Research, vol. 18, no. 6, p. e166, 2016.

[17] A. Holden, "Social media and professionalism: does the profession need to re-think the parameters of professionalism within social media?" Australian Dental Journal, vol. 62, no. 1, pp. 23-29, 2017.

[18] C. A. Boyle, T. Newton, and P. Milgrom, "Who is referred for sedation for dentistry and why?" British Dental Journal, vol. 206, no. 6, p. e12, 2009.

[19] W. Sohn and A. I. Ismail, "Regular dental visits and dental anxiety in an adult dentate population," The Journal of the American Dental Association, vol. 136, no. 1, pp. 58-66, 2005. 